\title{
Ethical responsibilities during undergraduate medical studies: A student's perspective
}

\author{
AYUSH ANAND, ASHWINI GUPTA
}

\begin{abstract}
All over the world, we see cases of violation of the code of ethical conduct by health professionals and students, leading to distrust between them and their patients. Institutions need to prioritise the training of students in biomedical ethics. Students face a variety of ethical issues throughout their course of study. Issues tend to vary from the pre-clinical years to the clinical years, depending upon the exposure to patients and teaching standards practised in institutions. There appears to be a gap between ethical issues discussed in classrooms and those faced by students in real life. Here we intend to provide a brief overview of the ethical responsibilities of a medical student in varied contexts. Knowing what their moral duties are will sensitise students to fundamental ethical principles in the medical field and lessen the gap between what is taught and what they will encounter in practice. Moreover, it will draw the attention of teachers towards the need to provide quality training in biomedical ethics.
\end{abstract}

Keywords: Ethics, biomedical ethics, responsibility, education

\section{Introduction}

The term ethics originates from the Greek word ethos, meaning "custom" or "character". Responsibility comes from the Latin verb 'respondere,' meaning "to respond". We see many cases of violation of the code of ethical conduct by health professionals. Unethical practices inevitably lead to a lack of trust between patients and health professionals and negatively impact both the patient and the doctor. Most cases of ethics-related challenges observed by students are

\section{Authors: Ayush Anand (corresponding author} ayushanandjha@gmail.com), Fourth Year MBBS Student and Head, Students' Bioethics Wing, BP Koirala Institute of Health Sciences, Dharan, NEPAL; Ashwini Gupta (aaswini108@gmail.com), Fourth Year MBBS Student and Member, Students' Bioethics Wing, BP Koirala Institute of Health Sciences, Dharan, NEPAL

To cite: Anand A, Gupta A. Ethical responsibilities during undergraduate medical studies: A student's perspective. Indian J Med Ethics. 2021 JulSep; 6(3) NS: 254-256. DOI: 10.20529/IJME.2021.001.

Published online first on January 23, 2021.

Manuscript Editor:Vijayaprasad Gopichandran

(C) Indian Journal of Medical Ethics 2021 related to ethical issues associated with medical education and professionalism (1). There is a gap between the ethical issues taken up for discussion in class and those that students actually encounter in real life (2). To avoid these problems in the future, we need to learn about biomedical ethics and devise a curriculum for the best possible ethical standards in future health professionals (3). In this article, we intend to discuss medical students' ethical responsibilities and draw attention to the related bioethical principles. Ethical issues addressed at the undergraduate level will prove vital for better healthcare, as we students are the future.

\section{Ethical responsibilities of a medical student in the pre-clinical years}

The human cadaver is the first teacher in anatomy. The cadaver, which sacrificed the right to cremation or burial, preserves life science even in death. It is an educational tool unparalleled by any other procurable to humankind. With increasing workload and frequent examinations, students tend to forget their debt to the cadaver, which is their ethical responsibility (4). The practice of taking an oath before the start of anatomical study and memorial ceremonies is helpful in strengthening students' moral values (5).

Students posted in laboratories during the pre-clinical years conduct several experiments and examine specimens. Every laboratory in medical college has some rules based on rational principles, which everyone has to follow. As individuals we do have autonomy; but autonomy without responsibility is no autonomy. Exercising autonomy without considering the benefit and harm caused by a particular decision is not an ethical practice. Following the universal precautions, wearing personal protective equipment, and following the instructions of experienced teachers will help us protect ourselves and our peers. For instance, we take blood samples from our peers to do testing in the physiology lab. During this process, we need to follow the process of informed consent, which is usually skipped. Overall, understanding and following the principles of autonomy, beneficence, non-maleficence, and taking informed consent will help avoid any harm caused directly or indirectly (6). This will help protect us from unnecessary exposure to harmful chemicals or infectious specimens. We also perform 
experiments on animals, and in that too, there is a need to follow the best ethical practice possible. Also, test results should not be used for discrimination and stigmatisation of patients and student volunteers and should be kept strictly confidential.

\section{Ethical responsibilities of a medical student in the clinical years}

In the clinical years of the undergraduate course, we are posted in various clinical departments to learn the necessary clinical skills required for doctors. These skills include taking a history, counseling patients, and management of patients in difficult situations. We learn to perform minor procedures during clinical postings, such as taking blood samples, urinary catheterisation, and giving injections. All these processes involve introducing ourselves to the patients and taking consent, except in emergencies where doctors have to decide for themselves. During emergency medicine postings, we perform cardiopulmonary resuscitation, laryngoscopy, intubation, and bag and mask ventilation under the guidance of seniors and teachers. There is a need to check if the patient has some legal document with "Do Not Resuscitate" instructions or a tattoo stating the same. All these involve critical thinking and understanding of the various ethical aspects involved. During this phase, exposure to many ethical dilemmas and lack of expertise in handling these dilemmas may lead to violation of moral principles, as such dilemmas were not actually discussed in the class setting and we may fail to make sound decisions.

Students may perform several unethical actions consciously or unconsciously. Some specific contexts in which this could happen are:

- The necessary first step before any medical procedure is taking informed consent. Students usually do not feel confident about taking informed consent on their own (7). A few may even perform a procedure with associated risks without taking informed consent from the patient. The informed consent process includes students or doctors introducing themselves, explaining the whole process in simple terms to the patient, and avoiding medical jargon. It is necessary to explain all the alternatives, benefits, and associated complications. It also involves an assessment of patients' understanding of the procedure.

- While visiting patients in the wards and outpatient departments, some students introduce themselves as doctors, while others provide inadequate information about their actual course. Students should realise that it is our ethical responsibility to provide accurate and complete facts while introducing ourselves to patients. If the patient later discovers that the provided information was inaccurate, she/ he may lose trust in doctors. Patients may even refuse treatment, which can cause direct harm to them. For example, a 3rd year student opens an IV route for drug administration and ends up poking the patient many times, as it is a first attempt. In this scenario, the patient is likely to lose confidence in the student, since he has been subjected to excessive pain. Moreover, in case of a mishap, the patient may take legal action against the student, which can prove to be very distressing. In such a case, if the student had introduced himself as a student in training, the patient would either have refused consent, or would be prepared for the consequences following the student's action. We should understand that we are not licensed to perform functions independently, as it could lead to a violation of both law and ethics.

- We often see a large number of students examining a single patient. Sometimes multiple examinations might cause discomfort to patients, especially those in severe pain or children. It may be psychologically distressing to answer the same questions repeatedly. This is against the principle of non-maleficence. To avoid any harm, we should work in small groups and take history or examine different patients. We can learn about an exceptionally rare or significant case at some other time. We should understand the ethical principles of beneficence and non-maleficence and evaluate the benefit and harm done to the patient before providing any information or performing a procedure. Students' Misinformation given by students may lead to physical, social or psychological stress for the patient.

- When we are presented with a problem about which we lack knowledge, our ethical responsibility is to consult with seniors and teachers and only then provide the required information. The operation theatre/intensive care unit is where the patients' situation is critical, and any contamination can lead to mortality. Here, our ethical responsibility is to understand the principles of nonmaleficence and follow all the standard rules and regulations.

- Every society is unique in a way, be it in beliefs, traditions, or taboos. Though some academic programmes have included the social determinants of health in their curriculum, most do not focus on the medical professional's cultural competence and how it affects healthcare quality (8). It is the ethical responsibility of a medical student to respect the patients' cultural diversity (9); because every patient is not just a human body but a whole individual who has come into existence with different norms and values. If we do not respect that, we are not going to heal the diseased completely. For eg, a Jehovah's Witness requires different treatments as their religious beliefs do not allow for blood transfusion or blood-related products. Such beliefs have to be respected as people don't come to doctors just for medicines; they come to be healed, and we need to have the compassion to heal them.

- Medical students may have a negative attitude towards the sick, such as those with mental illness (10) or sexually transmitted diseases. With increasing exposure to clinical settings, the level of stigmatisation reduces (11), but 
students should be made aware of these issues. As medical students and future health professionals, our responsibility is not to discriminate or stigmatise our patients based on their race, religion, gender, political beliefs, economic or social condition.

- Privacy and confidentiality are some of the most critical aspects of the medical professional - patient relationship. We often see health personnel involved in breaching the confidentiality of their patient (12). This unethical practice should be stopped, except in those privileged communications where a physician is concerned about the larger society's interests. Students often discuss a patient with their peers. Discussions are to be done being conscious of ethical responsibility to protect the privacy and confidentiality of patients.

- During postings in the forensic department, we come across cases of sexual violence. Also, we conduct several postmortem examinations under the guidance of our teachers. We should examine a person or a deceased while maintaining the highest ethical standards concerning their dignity and rights. We should respect autonomy by taking permission from the person concerned. Violation of ethical standards may lead to both professional misconduct and legal action.

Medical students have a better understanding of diseases prevalent in the community as compared to the general population. With knowledge comes responsibility. It is our ethical responsibility to educate the general population about various diseases and preventive measures to be taken. During field visits/community postings, patients expect a lot from the students. They might ask for medicines or may ask to check the patient's overall health. In these situations, we should know our limitations and assess our actions against the principles of beneficence and non-maleficence. Also, we should provide scientific information to the patients. Sometimes students may face communication problems due to different languages spoken in that area. In this situation, asking for help from friends and teachers is necessary to ensure that the message is correct.

In medical colleges, teachers often act as role models for students. We learn a lot from our teachers. It is our ethical responsibility to complete assignments and undergo proper training (theoretical and practical). As medical students, our commitment is not only to teachers and patients but also to our friends and juniors. We need to educate them and share with them information about various ethical issues. That is equally important in helping them achieve their goals. After all, we are all going to be health professionals, and we need to show solidarity.

\section{Conclusion}

Student life is one of the most crucial phases in the making of a healthcare professional, as the mistakes made then are opportunities to learn and be better prepared as future healthcare professionals. Undergraduate students have limited resources in terms of knowledge, skill and exposure, and as a result, they face challenges in the practical understanding of ethical principles. This makes it vital to develop strong ethical fundamentals in students from the beginning. On their part, students need to respect autonomy and evaluate beneficence and harm, follow the principles of non-maleficence, non-stigmatisation, and respect for patients' cultural diversity. This is central to delivering quality healthcare. Patients' privacy and confidentiality should be maintained, as also essential ethical standards in laboratories, dissection halls, wards, operation theatres, and out-patient departments.

\section{References}

1. Fard N, Asghari F, Mirzazadeh A. Ethical issues confronted by medical students during clinical rotations. Med Educ. 2010 Jul;44(7): 723-30. doi:10.1111/j.1365-2923.2010.03671.x

2. Muhaimin A, Willems D, Utarini A, Hoogsteyns M. What do students perceive as ethical problems? A comparative study of Dutch and Indonesian medical students in clinical training. Asian Bioeth Rev. 2019;11(4):391-408. Doi:10.1007/s41649-019-00101-6

3. Liu E, Batten J, Merrell S, Shafer A. The long-term impact of a comprehensive scholarly concentration program in biomedical ethics and medical humanities. BMC Med Educ. 2018 Aug 28;18(1): 204. Doi: 10.1186/s12909-018-1311-2.

4. Chang H, Kim H, Rhyu I, Lee $\mathrm{Y}$, Uhm C. Emotional experiences of medical students during cadaver dissection and the role of memorial ceremonies: a qualitative study. BMC Med Educ. 2018 Nov12;18(1):1-7.doi:10.1186/s12909-018-1358-0

5. Ghosh S. Paying respect to human cadavers: We owe this to the first teacher in anatomy. Ann Anat. 2017 May; 211:129-34. Doi:10.1016/ j.aanat.2017.02.004.

6. Gronowski A, Budelier M, Campbell S. Ethics for laboratory medicine. Clin Chem. 2019 Dec 1;65(12):1497-507. Doi:10.1373/clinchem. 2019.306670.

7. Anderson T, Aalami L, Lee E, Merrell S, Sgroi M, Lin D et al. Perception and confidence of medical students in informed consent: $A$ core EPA. Surgery. 2020 Apr;167(4):712-6. Doi:10.1016/j.surg.2019.11.012

8. Sorensen J, Norredam M, Suurmond J, Carter-Pokras O, GarciaRamirez M, Krasnik A. Need for ensuring cultural competence in medical programmes of European universities. BMC Med Educ. 2019;19(1):1-8.doi:10.1186/s12909-018-1449-y

9. Alni J, Borhani F, Ebadi A, Bazmi S. Professional ethical competence for medical students: A qualitative study. Electron J Gen Med. 2018 Feb 19;15(3).Doi:10.29333/ejgm/85497

10. Eksteen H, Becker P, Lippi G. Stigmatization towards the mentally ill: Perceptions of psychiatrists, pre-clinical and post-clinical rotation medical students. Int J Soc Psychiatry. 2017 Oct 25; 63(8):782-91. Doi: $10.1177 / 0020764017735865$

11. Fujii T, Hanya M, Kishi M, Kondo $Y$, Cates M, Kamei H. An internetbased survey in Japan concerning social distance and stigmatization toward the mentally ill among doctors, nurses, pharmacists, and the general public. Asian J Psychiatr. 2018 Aug; 36:1-7.Doi:10.1016/j.ajp.2018.05.017

12. Beltran-Aroca C, Girela-Lopez E, Collazo-Chao E, Montero-PérezBarquero M, Muñoz-Villanueva M. Confidentiality breaches in clinical practice: what happens in hospitals?. BMC Med Ethics. 2016 Sep 2;17(1):52.doi:10.1186/s12910-016-0136-y. 